\title{
NON-STRESS TEST- A PREDICTION OF NEONATAL OUTCOME
}

\author{
Sonal Agarwal ${ }^{1}$, Anurag Aggarwal ${ }^{2}$
}

${ }_{1}^{1}$ Senior Resident, Department of Obstetrics and Gynaecology, ESI Hospital, Faridabad, Haryana, India.

${ }^{2}$ Senior Resident, Department of Internal Medicine, Fortis Hospital, Faridabad, Haryana, India.

ABSTRACT
BACKGROUND
Intrapartum foetal monitoring to assess foetal well-being during labour and delivery process has been a central component of
intrapartum care for decades.
$\quad$ The aim of the study was to evaluate the role of Non-Stress Test (NST) in intrapartum foetal monitoring and to assess its role in
predicting neonatal outcome.

\section{MATERIALS AND METHODS}

A prospective observational study was conducted in the Department of Obstetrics and Gynaecology in Subharti Medical College and Associated Hospital, Meerut, for two years on 150 women. Pregnant women who came in labour were selected for the study. All women were subjected to NST. At delivery, Apgar score at 1 and 5 minute, cord blood pH and neonatal ICU admissions were noted.

\section{RESULTS}

NST showed a high sensitivity of $93 \%$ and a specificity of $69 \%$ in predicting neonatal outcome. The diagnostic accuracy of NST was 84.8\%. Every neonate born to the mother with non-reactive NST had severe acidosis and required NICU admission.

\section{CONCLUSION}

It was concluded that NST had a high diagnostic accuracy in predicting neonatal outcome.

\section{KEY WORDS}

Non-Stress Test, Intrapartum Care, Neonatal Outcome, Lower Segment Caesarean Section.

HOW TO CITE THIS ARTICLE: Agarwal S, Aggarwal A. Non-stress test- a prediction of neonatal outcome. J. Evolution Med. Dent. Sci. 2018;7(34):3796-3798, DOI: 10.14260/jemds/2018/851

\section{BACKGROUND \\ Foetal asphyxia is a condition of disturbed gas exchange,} leading to progressive hypoxemia and hypercapnia with significant metabolic acidosis. Forty-nine lakh cases of newborn asphyxia occur each year. ${ }^{1}$ Intrapartum foetal monitoring to assess foetal well-being during labour and delivery process has been a central component of intrapartum care for decades. Cardiotocography (CTG) is a continuous recording of foetal heart rate obtained via an ultrasound transducer placed on mother's abdomen. The main justification for admission CTG is that the uterine contractions of labour places stress on placental circulation. An abnormal tracing indicates a deficiency and hence identifies foetal compromise at an early enough stage to allow intervention. NST with improved acoustic stimulation is a convenient,fast, safe and effective method of detecting false non-reacting NST and it increases the specificity of NST. Normal umbilical cord $\mathrm{pH}$ is 7.2 to 7.4. Milder degrees of hypoxia/ acidosis correspond to $\mathrm{pH}$ values between 7.0 and 7.20 , while a pH below 7.0 denotes severe asphyxia and is associated with neurological dysfunction and neonatal deaths. Apgar score (Dr. Virginia Apgar-1953) is a scoring procedure for better understanding of clinical state of foetus. This also helps in comparison of results and standardisation of methods of management.

'Financial or Other Competing Interest': None.

Submission 19-06-2018, Peer Review 05-08-2018,

Acceptance 11-08-2018, Published 20-08-2018.

Corresponding Author:

Dr. Anurag Aggarwal,

H. No. 74, Sector-23,

NIT, Faridabad-121005, Haryana, India.

E-mail: anurag.mamc@gmail.com

DOI: $10.14260 /$ jemds $/ 2018 / 851$
Apgar scoring is done in a new-born baby at 1 and 5 minutes. Long-term neurological correlation is obtained at 5minute score, which is of more value. We hence conducted this study to compare the predictive accuracy of assessing intrapartum cardiotocography of foetus in detecting foetal hypoxia and to correlate their results (outcome) with the perinatal outcome such as Apgar score, foetal $\mathrm{pH}$ analysis and Neonatal ICU (NICU) admissions.

\section{Aim}

The aim of the study was to evaluate the role of NST in intrapartum foetal monitoring in predicting neonatal outcome by analysing neonate cord blood acidosis, their Apgar score and the rate of NICU admissions at birth.

\section{MATERIALS AND METHODS}

This was a prospective observational study, which included 150 pregnant women in labour. Ethical clearance was taken for the study from the Institutional Ethical Committee. Each subject was informed about the nature of the study and a written informed consent was taken.

Inclusion criteria were pregnancy $>37$ weeks irrespective of the parity, singleton pregnancy with cephalic presentation, both high and low risk pregnancy, high risk cases comprising of gestational diabetes mellitus, preeclampsia, prolonged rupture of membrane, post-dated, Rh negative pregnancy, oligohydramnios and polyhydramnios.

Exclusion criteria for study group were pregnancy $<37$ weeks of gestation, pregnancy with known congenital anomalies, multiple pregnancies, malpresentations and intrauterine death.

On admission after written and informed consent, woman's detailed history including age, parity, antenatal history, menstrual, obstetric and medical history was 
documented, and general physical examination was done. Per abdominal examination was performed following which mothers were subjected to cardiotocography test and a repeat test was done if only abnormalities in the foetal heart rate were identified. Two belts were placed around patient's abdomen, the foetal transducer was placed at the location where the foetal heart was best localised and the toco transducer was placed at the fundus of the uterus and CTG tracing was recorded for a span of 20 minutes. CTG monitoring was extended for 10 mins, if required in case of equivocal reading. At delivery, Apgar score at 1 and 5 mins and admission to neonatal unit and its indication foetal $\mathrm{pH}$ analysis was noted. Neonatal ICU admission for more than 24 hours was considered significant for study. Immediately after the delivery of the baby, blood was taken from umbilical cord and sample was collected in a heparinised syringe and was used for $\mathrm{pH}$ estimation which was done by doing arterial blood gas analysis.

All necessary information and clinical data were systematically recorded on predesigned proforma sheet to substantiate the correct information and record. The data obtained from the study group was analysed and statistically verified.

\section{Statistical Analysis}

The data were entered into the computer and analysed by using the Statistical Package for Social Sciences (SPSS) version 10.0 programs for Windows. Chi-square test was used to calculate the percentage and frequency. The significance value was achieved at $\mathrm{p}<0.05$.

\section{RESULTS}

This study was conducted on 150 pregnant women who presented to Subharti Medical College in labour with an intent to evaluate the role of cardiotocography for intrapartum foetal monitoring. All the women underwent NST analysis. The demographics of study population is described in Table No. 1.

Seventy eight percent of the studied women had one or other high-risk factor. High risk factors seen in women included anaemia, pregnancy with previous LSCS, post-dated pregnancy, premature rupture of membranes, oligohydramnios, hypertensive disorders of pregnancy etc. Among 150 women, 75\% (112/150) had normal vaginal delivery and 25\% (38/150) underwent LSCS.

The neonatal cord blood was collected and sent for $\mathrm{pH}$ analysis. Sixty three percent neonates had normal cord blood $\mathrm{pH}(\mathrm{pH}>7.2), 23 \%$ (34/150) had mild acidosis with $\mathrm{pH} 7-7.2$ and $15 \%(22 / 150)$ women had severe acidosis ( $\mathrm{pH}<7)$. Twenty five percent $(37 / 150)$ neonates had NICU admission.

Among the 94 neonates who had normal cord blood $\mathrm{pH}$ (Figure 1, 2), 90\% had NST Category I, 5\% had NST Category II and $4.25 \%$ had NST Category III (Figure 1).

Among the neonates who had mild acidosis, maximum had NST of Category I (82\%), fourteen percent had Category II and 3\% had Category III.

Among the neonates who had severe acidosis, $4.5 \%$ had Category I NST, 50\% neonates had Category II and 45\% had Category III NST.

Thus, the sensitivity of NST was found to be $93 \%$, specificity was $69.4 \%$ and the diagnostic accuracy of NST in predicting neonatal outcome (Figure 2), (Table 2) was $84.8 \%$.

\begin{tabular}{|c|c|c|}
\hline $\begin{array}{l}\text { Age Group } \\
\text { (Year) }\end{array}$ & $\begin{array}{c}\text { Number of Women } \\
(\mathrm{N}=150)\end{array}$ & $\begin{array}{c}\text { Percentage } \\
(\%)\end{array}$ \\
\hline$\leq 25$ & 53 & 35.3 \\
\hline $25.1-30$ & 65 & 43.3 \\
\hline $30.1-35$ & 27 & 18.0 \\
\hline $35.1-40$ & 5 & 3.3 \\
\hline $\begin{array}{c}\text { Body Mass Index } \\
\left(\mathrm{kg} / \mathrm{m}^{2}\right)\end{array}$ & $\begin{array}{c}\text { Number of Women } \\
(\mathrm{N}=150)\end{array}$ & $\begin{array}{c}\text { Percentage } \\
(\%)\end{array}$ \\
\hline$\leq 19$ & 33 & 22.0 \\
\hline $19.1-24$ & 117 & 78.0 \\
\hline 24.1-29 & 0 & 0.0 \\
\hline Education & $\begin{array}{c}\text { Number of Women } \\
(N=150)\end{array}$ & $\begin{array}{c}\text { Percentage } \\
(\%)\end{array}$ \\
\hline Illiterate & 36 & 24.0 \\
\hline Primary education & 63 & 42.0 \\
\hline $\begin{array}{c}\text { Secondary } \\
\text { education }\end{array}$ & 26 & 17.3 \\
\hline $\begin{array}{c}\text { Graduate/ } \\
\text { Postgraduate }\end{array}$ & 25 & 16.7 \\
\hline Domicile & $\begin{array}{c}\text { Number of Women } \\
(N=150)\end{array}$ & $\begin{array}{c}\text { Percentage } \\
(\%)\end{array}$ \\
\hline Rural & 81 & 54.0 \\
\hline Urban & 69 & 46.0 \\
\hline High Risk Factors & Number of Women & $\begin{array}{c}\text { Percentage } \\
(\%)\end{array}$ \\
\hline None & 42 & 28.0 \\
\hline Anaemia & 30 & 20.0 \\
\hline Previous LSCS & 18 & 12.0 \\
\hline Post-dated & 16 & 10.7 \\
\hline $\begin{array}{c}\text { Premature rupture } \\
\text { of membranes }\end{array}$ & 8 & 5.3 \\
\hline Oligohydramnios & 7 & 4.7 \\
\hline $\begin{array}{c}\text { Hypertensive } \\
\text { disorders of } \\
\text { pregnancy }\end{array}$ & 7 & 4.7 \\
\hline $\begin{array}{c}\text { Cholestasis of } \\
\text { pregnancy }\end{array}$ & 6 & 4.0 \\
\hline $\begin{array}{c}\text { Rh Negative } \\
\text { pregnancy }\end{array}$ & 6 & 4.0 \\
\hline Hypothyroidism & 4 & 2.7 \\
\hline $\begin{array}{c}\text { Meconium stained } \\
\text { liquor }\end{array}$ & 4 & 2.7 \\
\hline $\begin{array}{c}\text { Antepartum } \\
\text { haemorrhage }\end{array}$ & 1 & 0.7 \\
\hline Epilepsy & 1 & 0.7 \\
\hline
\end{tabular}

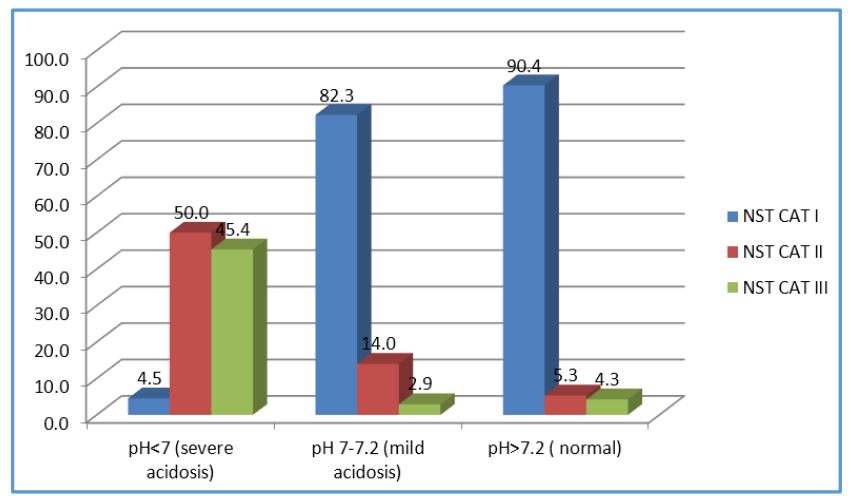

Figure 1. Correlation of Foetal Acidosis with NST 


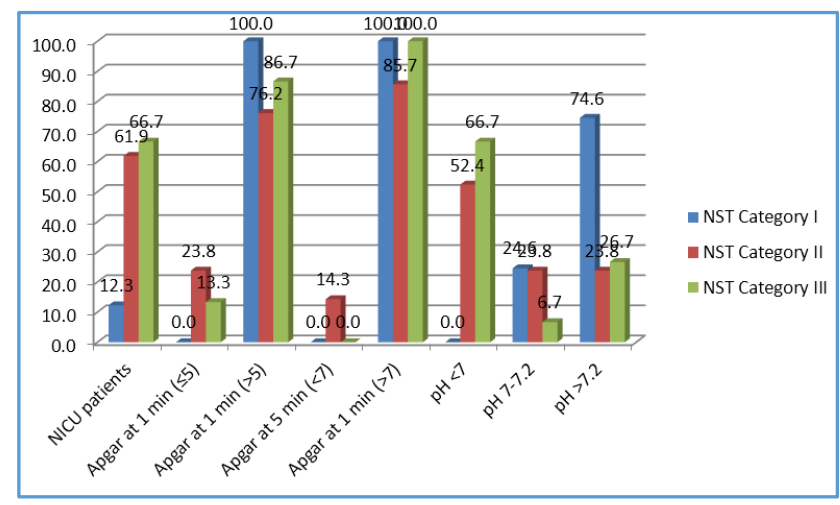

Figure 2. Correlation of NST with Good Neonatal Outcome

\begin{tabular}{|c|c|c|c|c|c|}
\hline $\begin{array}{c}\text { Test } \\
\text { Variable }\end{array}$ & $\begin{array}{c}\text { Cut-Off } \\
\text { Value }\end{array}$ & $\begin{array}{c}\text { Sensiti- } \\
\text { vity }\end{array}$ & $\begin{array}{c}\text { Specifi- } \\
\text { city }\end{array}$ & Accuracy & P Value \\
\hline $\begin{array}{c}\text { Apgar } \\
\text { score at 1 } \\
\text { min }\end{array}$ & $\geq 6.5$ & $95.6 \%$ & $55.6 \%$ & $77.0 \%$ & 0.002 \\
\hline $\begin{array}{c}\text { Apgar } \\
\text { score at } 5 \\
\text { mins }\end{array}$ & $\geq 8.50$ & $86.0 \%$ & $63.9 \%$ & $76.9 \%$ & 0.018 \\
\hline $\begin{array}{c}\text { Cord pH } \\
\text { level }\end{array}$ & $\geq 7.12$ & $93.0 \%$ & $69.4 \%$ & $84.8 \%$ & 0.021 \\
\hline
\end{tabular}

\section{DISCUSSION}

Our surveillance system must detect compromised foetuses and ensure their safe delivery. So concept of antepartum and intrapartum surveillance is executed with the primary focus being foetal heart rate assessment. Today, Electronic Foetal Monitoring (EFM) is the most common method used to assess the foetus during labour. ${ }^{3}$

Anjali Verma et $\mathrm{al}^{4}$ studied 326 women in Geetanjali Medical College, Udaipur. The patients were subjected to Admission Stress Test (AST). Perinatal morbidity in reactive, equivocal and non-reactive group was $4.8 \%, 28.94 \%$ and $55.92 \%$ respectively. Their result was similar to our group.

Rahman $\mathrm{H}$ et $\mathrm{al}^{5}$ (2012) studied admission cardiotocography and its role in predicting foetal outcome in high-risk obstetric patients. Like our study, their result showed that $11.3 \%(14 / 123)$ babies from mothers in the reactive Admission Time (AT) group, 39.1\% (9/23) of babies from the equivocal group and $85.7 \%(12 / 14)$ babies from the ominous group showed evidence of foetal distress.

Puneeta Kaur et al ${ }^{6}$ evaluated the role of NST and VAST in high risk pregnancy in predicting perinatal outcome and evaluated vibroacoustic stimulation test as a screening test for early intrapartum foetal monitoring in 2015. High risk pregnant women showed that $75 \%$ cases had positive test which included (reactive NST with reactive VAST and also reactive VAST over non-reactive NST), out of which $82.6 \%$ were with favourable perinatal outcome and $17.3 \%$ with unfavourable perinatal outcome. Their results were similar to our study and showed that NST and VAST had high sensitivity and specificity in predicting neonatal outcome.
Praveen Shreshta (2015) et $\mathrm{al}^{7}$ did a prospective study at the Department of Obstetrics and Gynaecology, Manipal Teaching Hospital, Pokhara, Nepal. The aim of the study was to identify effectiveness of NST in detecting high risk foetus, thus preventing perinatal morbidity and mortality. Most of the patients (71) belonged to 20 to 35 years' age group, which was similar to our study. There were 43 patients aged more than 35 years and 11 were less than 20 years of age. The mean age was 25 years.

Hafizurrahman et $\mathrm{al}^{5}$ conducted a study to evaluate the predictive value of cardiotocogram (CTG) with the perinatal outcome in high-risk obstetric cases. In detecting foetal hypoxia at the time of admission in labour and to correlate the results of the admission, CTG studied role in predicting foetal outcome in obstetric patients. This study was conducted in labour and maternity ward of a hospital in Gangtok, India during the period 2008 - 2010. One hundred and sixty women were recruited in the study. Most women were in the 21 - 30 years' age group. It was again similar to our study, which had maximum number of patients in age group 25 - 30 years.

\section{CONCLUSION}

It was concluded that non-stress test has high diagnostic accuracy in predicting neonatal outcome. However, further studies are needed to detect compromised foetuses and ensure their safe delivery.

\section{REFERENCES}

[1] Bunocore G, Bracci R, Weindling M. Neonatology: a practical approach to neonatal diseases. Italia: Springer-Verlag 2011;83:621-8.

[2] Sambarey P, Bilagi DM. Non-stress test and vibroacoustic stimulation test in high-risk pregnancies and its relation to perinatal outcome. International Journal of Scientific Study February 2016;3(11):173-7.

[3] Cahill AG, Spain J. Intrapartum fetal monitoring. Clin Obstet \& Gynecol 2015;58(2):263-8.

[4] Verma A, Shrimali L. Impact of admission non stress test as a screening procedure on perinatal outcome. IJMPS 2012;3(5):06-10.

[5] Arora PK, Bhatnagar B. Comparison of vibroacoustic stimulation test and non-stress test in high risk pregnancies. Journal of Evolution of Medical and Dental Sciences 2015;4(48):8278-82.

[6] Rahman H, Renjhen P, Dutta S, et al. Admission cardiotocography: its role in predicting foetal outcome in high-risk obstetric patients. Australas Medical Journal 2012;5(10):522-7.

[7] Shreshta P, Misha M, Shrestha S. A prospective study on impact of non- stress test in prediction of pregnancy outcome. American Journal of Public Health Resources 2015;3(4A):45-8. 